\title{
Thick Low-Friction nc-MeC/a-C Nanocomposite Coatings on Ti-6Al-4V Alloy: Microstructure and Tribological Properties in Sliding Contact with a Ball
}

\author{
SŁAWOMIR ZIMOWSKI, TOMASZ MOSKALEWICZ, BOGDAN WENDLER, \\ MARCIN KOT, and ALEKSANDRA CZYRSKA-FILEMONOWICZ
}

In this paper, we show that duplex surface treatment, combining oxygen diffusion hardening with the subsequent deposition of thick, low-friction nanocomposite $\mathrm{nc}-\mathrm{MeC} / \mathrm{a}-\mathrm{C}$ coatings to improve the tribological properties of the Ti-6Al-4V alloy. We have synthesized, in a magnetron sputtering process, the nanocomposite nc-MeC/a-C coatings (where Me denotes $\mathrm{W}$ or $\mathrm{Ti}$ transition metal) consisting of two dissimilar materials (nanocrystallites of transition metal carbides $\mathrm{MeC}$ and an amorphous carbon matrix a-C). The nano and microstructure of the substrate material and coatings were examined with the use of scanning and transmission electron microscopy as well as by X-ray diffractometry. It was found that different carbide nanocrystals of the same transition metal were embedded in an amorphous carbon matrix of both coatings. The HRTEM analysis indicated that the volume fraction of tungsten carbides in the nc-WC/a-C coating was equal to $13 \mathrm{pct}$, whereas in the nc-TiC/a-C one the volume fraction of the titanium carbides was equal to just 3 pct. The tribological properties, hardness, and scratch resistance of the coatings were investigated as well. The coefficient of friction (COF) of the coatings during dry sliding against $6 \mathrm{~mm}$ diameter alumina ball reached very low value, 0.05 , in comparison with an oxygen-hardened alloy, whose COF was equal to 0.8 . This lowfriction effect of the coatings has been attributed to the formation of a self-lubricating film in sliding contact. The coatings exhibited similar failure morphology in the scratch tests. Even though the hardness was rather low, the coatings exhibited a very good wear resistance during sliding friction. The wear rate of the nc-WC/a-C coating was equal to $0.08 \times 10^{-6} \mathrm{~mm}^{3} \mathrm{~N}^{-1} \mathrm{~m}^{-1}$ and for the nc-TiC/a-C one it was $0.28 \times 10^{-6} \mathrm{~mm}^{3} \mathrm{~N}^{-1} \mathrm{~m}^{-1}$.

DOI: $10.1007 / \mathrm{s} 11661-014-2333-\mathrm{y}$

(C) The Author(s) 2014. This article is published with open access at Springerlink.com

\section{INTRODUCTION}

CARBON-BASED nanocomposite coatings have been intensively investigated in the last decade due to the possibility of synthesis of numerous new materials with unique properties. A general feature of such nanocomposite coatings is a host amorphous carbon matrix with inclusions of another phase or phases (crystalline or amorphous) uniformly embedded in it, with one (or more) of these items having a characteristic length scale of the range $1 \div 100 \mathrm{~nm}^{[1]}$ Low-friction nanocomposite coatings based on the dispersion of

SŁAWOMIR ZIMOWSKI and MARCIN KOT, Assistant Professors, are with the Faculty of Mechanical Engineering and Robotics, AGH University of Science and Technology, Al. Mickiewicza 30, 30-059 Kraków, Poland. Contact e-mail: zimowski @ imir.agh.edu.pl TOMASZ MOSKALEWICZ, Assistant Professor, and ALEKSANDRA CZYRSKA-FILEMONOWICZ, Professor, are with the Faculty of Metals Engineering and Industrial Computer Science, International Centre of Electron Microscopy for Materials Science, AGH University of Science and Technology, Al. Mickiewicza 30, 30-059 Kraków, Poland. BOGDAN WENDLER, Professor, is with the Faculty of Mechanical Engineering, Technical University of Lodz, Stefanowskiego 1/15, 90-924 Lodz, Poland.

Manuscript submitted September 28, 2013.

Article published online May 17, 2014 titanium or tungsten nanocrystalline carbides in a solid lubricant phase, such as amorphous carbon a-C, have a relatively low coefficient of friction (COF), reasonably high hardness and a high resistance to wear. ${ }^{[2-5]}$

Understanding the nano/microstructure of the lowfriction coating is important while establishing the processing-microstructure-properties relationship necessary to develop effective low-friction systems. By controlling the size and volume fraction of hard nanocrystalline inclusions in a softer, amorphous matrix and, as a result, the spacing between the nanocrystalline carbides embedded in the matrix, the tribological properties of the nanocomposite coatings might be easily tailored. A decrease in the COF and simultaneous increase in the wear resistance of coated components should increase the life-time and reliability of machine parts and reduce operating costs. In addition, implementation of self-lubricating $\mathrm{nc}-\mathrm{MeC} / \mathrm{a}-\mathrm{C}$ coatings allows users to reduce the use of costly lubricants, eliminate harmful oil waste and has a significant beneficial effect on environmental protection. ${ }^{[2,6]}$

The performance of nanocomposite coatings with a low COF is strongly influenced by their micro/nanostructure. ${ }^{[7,8]}$ The micro/nanostructure characterization of thin coatings is essentially a complex task and can be best performed by means of advanced transmission 
electron microscopy (TEM). Advanced TEM allows precise phase identification in multiphase and/or multilayered materials with a spatial resolution down to the nano-scale. Analytical electron microscopy simultaneously gains information about the morphology, crystallography, and chemical composition of the investigated phases..$^{[9,10]}$ In the present study, analytical TEM and high-resolution TEM (HRTEM) were applied for micro/nanostructure characterization of low-friction nanocomposite coatings on a Ti-6Al-4V alloy. Knowledge about the micro/nanostructure of the coatings allows for a full interpretation of the micromechanical and tribological properties, as well as the phenomena observed during friction.

In order to improve the load-bearing properties of the two $(\alpha+\beta)$ phase Ti-6Al-4V substrate material, a hard oxygen-rich diffusion layer was produced in the near-tosurface zone of the alloy of a thickness of several dozens of micrometers. As reported in the literature ${ }^{[11,12]}$ such surface treatment can provide adequate mechanical support for a relatively thin hard top nanocomposite coating.

The present work is focused on:

(i) a detailed characterization of the nano/microstructure of thick nc-WC/a-C and nc-TiC/a-C coatings deposited on an oxygen-hardened Ti-6Al-4V alloy by DC magnetron sputtering as well as determination of their hardness and scratch resistance,

(ii) investigation of the frictional behavior and the wear mechanism of the nc-WC/a-C and nc-TiC/a$\mathrm{C}$ coatings in sliding contact with the ball related to their mictrostructure and micromechanical properties.

\section{MATERIAL AND EXPERIMENTAL PROCEDURE}

The investigation was performed on a commercial two-phase $(\alpha+\beta)$ titanium alloy Ti-6Al-4V of the following chemical composition (in wt pct): $\mathrm{Al}-6.15$; $\mathrm{V}-4 ; \mathrm{Fe}-0.18 ; \mathrm{N}-0.01 ; \mathrm{C}-0.03 ; \mathrm{O}-0.12 ; \mathrm{H}-0.005$; Ti-balance. It was delivered as a hot rolled and vacuum annealed [at $1023 \mathrm{~K}\left(749.9^{\circ} \mathrm{C}\right)$ for 2 hours] by BÖHLER Edelstahl GmbH, Germany. The alloy microstructure consisted of elongated grains of the Ti $\alpha$ phase (hexagonal close-packed; hcp) of a length up to $2 \mu \mathrm{m}$ and of grains of the Ti $\beta$ phase (body-centered cubic; bcc) of a size of about $0.5 \mu \mathrm{m}$. The Ti-6Al-4V specimens were subsequently surface treated by oxidation at $1173 \mathrm{~K}\left(899.9^{\circ} \mathrm{C}\right)$ in the $\mathrm{Ar}+\mathrm{O}_{2}$ atmosphere enhanced with a DC plasma glow discharge. ${ }^{[12]}$ During such treatment, the Ti $\alpha$ and Ti $\beta$ grains increased up to 15 and $5 \mu \mathrm{m}$, respectively. In addition, the grain morphology of both phases was changed from elongated to equiaxed. A near-to-surface region of the alloy consisted of a diffusion zone, i.e., the $\operatorname{Ti} \alpha(\mathrm{O})$ solid solution with interstitial oxygen atoms. Based on the EDS analysis, the $\operatorname{Ti} \alpha(\mathrm{O})$ zone of the hardened alloy after grinding exhibited a minimum thickness of $30 \mu \mathrm{m}$, which also confirmed the results of microhardness tests on a cross-section of the alloy. A detailed description of the oxygen-hardened microstructure and mechanical properties of the Ti-6Al-4V alloy were given by Moskalewicz et al. ${ }^{[2]}$ As written elsewhere, ${ }^{[2]}$ after oxygen hardening, the hardness of the alloy increased from 3.4 GPa for the baseline alloy to $10.6 \mathrm{GPa}$ for treated one, while the elastic modulus reached $190 \mathrm{GPa}$. The wear resistance in dry sliding contact was also improved. The wear rate for the baseline alloy equaled $647 \times 10^{-6} \mathrm{~mm}^{3} \mathrm{~N}^{-1} \mathrm{~m}^{-1}$ and was diminished after hardening to $2.5 \times 10^{-6} \mathrm{~mm}^{3} \mathrm{~N}^{-1} \mathrm{~m}^{-1}$. The friction coefficient of the oxygen-hardened alloy against an alumina ball was equal to 0.2 but only in the initial period of cooperation up to 2000 cycles and subsequently reached the value of $0.8 .{ }^{[13]}$ Thus, as it was stated before, the hardening effect improving the parameters of the material, results from the solid solution strengthening combined with the solution of oxygen in the Ti $\alpha$ phase.

The nanocomposite nc-WC/a-C and nc-TiC/a-C coatings were deposited onto the oxygen-hardened Ti-6Al$4 \mathrm{~V}$ alloy by magnetron sputtering. The Ti-6Al-4V alloy substrates before and after the oxygen hardening were mirror polished. Before deposition, the substrates were grounded with the use of silicon carbide sandpaper with successively decreasing grit size up to 2000, and next polished on a cloth-coated disk with diamond paste at a grain size of $1 \mu \mathrm{m}$ with the admixture of a lubricant. The grinding and polishing process was performed easily with the use of fine-grained materials and, after it, the hardness of the treated (hardened) alloy was controlled. The mirror flatness surface of the polished substrate $\left(R_{\mathrm{a}}<0.01 \mu \mathrm{m}\right)$ and resulted homogeneity of the surface texture did not influence the deposition process. The only reason for the substrate treatment was to increase the hardness of the near-to-surface zone of the substrate.

The specimens prepared that way were suspended under the rotary table in the center of the vacuum chamber of a B90 multipurpose magnetron sputtering unit equipped with four circular magnetrons with high purity targets of a $100 \mathrm{~mm}$ diameter and $9 \mathrm{~mm}$ thickness: one made of tungsten (of purity $4 \mathrm{~N}$ ), one of titanium (of purity $3 \mathrm{~N}$ ) and two of graphite (of purity $4 \mathrm{~N}$ ). The optimal process parameters were selected from the series of experiments published in earlier papers. ${ }^{[2,3,6,14]}$ The process parameters during deposition of the nc-WC/a-C coating were as follows: the power of the magnetron with the $\mathrm{W}$ target was equal to $0.25 \mathrm{~kW}$ and that for the magnetrons with graphite targets was $2.1 \mathrm{~kW}$ (of each one of both) at an $\mathrm{Ar}$ pressure of $0.55 \mathrm{~Pa}$. During deposition of the nc-TiC/a-C coating, the power of the magnetron with the Ti target amounted to $0.3 \mathrm{~kW}$ and for the magnetrons with graphite targets it was equal to $1.55 \mathrm{~kW}$ (for each one) at an Ar pressure of $0.4 \mathrm{~Pa}$. To improve the coatings' adhesion to the substrate, at first a thin intermediate gradient layer was deposited. The composition of this layer changed from the pure metallic $\mathrm{W}$ or $\mathrm{Ti}$ and ended with a composition of the complete nc-WC/a-C or nc-TiC/a-C coating, respectively. During deposition, the substrates were biased with a negative unipolar sinusoidal potential of a medium frequency of $150 \mathrm{kHz}$ and amplitude of $50 \mathrm{~V}$ 
modulated at a frequency of $2 \mathrm{kHz}$. The resulting bias current changed in the range of 100 to $130 \mathrm{~mA}$. Several deposition processes of both coatings were performed for optimization of the deposition parameters. ${ }^{[6,14]}$

The investigation of the coated alloy nano/microstructure was carried out with use of the scanning and transmission electron microscopy (SEM and TEM) as well as by X-ray diffractometry (XRD) and grazing incidence X-ray diffractometry (GIXRD). The SEM investigation was performed using a Zeiss $\mathrm{NEON}^{\circledR}$ CrossBeam 40EsB. Analytical TEM and HRTEM investigations were carried out with use of JEOL JEM-2010 ARP (200 kV) and ARM 1250 (1250 kV) microscopes on cross-section lamellas. The lamellas were prepared by a Focused Ion Beam (FIB) NEON CrossBeam 40EsB, followed by short ion-beam thinning using the precision ion polishing system (PIPS) of Gatan. The XRD (Bragg-Brentano, B-B) and GIXRD patterns were recorded using a Siemens D500 Kristalloflex diffractometer with use of $\mathrm{Cu} \mathrm{K} \mathrm{K}_{\alpha}$ radiation and plane-view specimens.

Phase identification was performed by means of selected area electron diffraction (SAED), XRD, and GIXRD techniques. The SAED and fast Fourier transform (FFT) patterns were interpreted with the help of Java Electron Microscopy Software (JEMS). ${ }^{[15]}$ The phase identification was supplemented by energy dispersive X-ray spectrometry (STEM-EDS). The STEM images of the size of $512 \times 512$ pixels were acquired with use of an electron beam of a size of approximately $3 \mathrm{~nm}$. Image analysis was performed using GATAN "Digital Micrograph" software. The thickness of lamellas was determined by means of electron energy loss spectroscopy (EELS). The particle's size and its distribution were determined based on a number of HRTEM micrographs supported by AnalySIS 3.1 software. $^{[16]}$

Tribological tests were carried out in a ball-on-disk configuration in two modes - at a constant load in rotation and at a progressive load in translational motion. The coated titanium alloy disks were dry sliding against an alumina ball of $6 \mathrm{~mm}$ diameter in static air of a relative humidity ( $\mathrm{RH}) 50 \pm 5$ pct under normal pressure at a temperature of $295 \pm 1 \mathrm{~K}\left(22 \pm 1{ }^{\circ} \mathrm{C}\right)$. Tests in rotation motion were carried out on a ball-ondisk tribometer under a normal load $(F)$ of $2.5 \mathrm{~N}$. The wear track radius was $5 \mathrm{~mm}$, the rotation speed of the disk was $120 \mathrm{rpm}$ and the total number of revolutions of the disk was 20,000. Tests in translational motion were conducted on a ball-on-plane tribometer under a progressive load from 0 to $30 \mathrm{~N}$ on the path of $3 \mathrm{~mm}$ with the speed of $15 \mathrm{~mm} / \mathrm{min}$. Before the experiments, the ball and the coated disk were washed in acetone in an ultrasonic bath and dried in a flow of dry nitrogen. The tests were repeated three times and the reported friction and wear values are the mean ones. The wear volume of any specimen was calculated on the basis of the crosssectional profile of the wear track measured with the use of a stylus profilometer and integrated over the length of the groove. Wear rate $\left(W_{\mathrm{V}}\right)$ was determined as the volume $(V)$ of the removed coating material in relation to the applied load and to the total length of the friction distance. The wear scars of the coatings and balls were observed as well using light microscopy (LM).

Hardness and elastic modulus were determined by means of an instrumented indentation test with use of a CSM Micro Combi Tester (MCT) with a Vickers diamond pyramid at a load of $10 \mathrm{mN}$. This load provides the penetration depth of the indenter below 10 pct of the coating thickness. According to the OliverPharr method, the reduced modulus, $E_{\mathrm{r}}$, which is calculated from the indentation data, is defined as ${ }^{[17,18]}$.

$$
E_{\mathrm{r}}=\frac{\sqrt{\pi} \cdot S_{\mathrm{con}}}{2 \cdot \beta \cdot \sqrt{A\left(h_{\mathrm{c}}\right)}},
$$

where $S_{\mathrm{con}}=\mathrm{d} P / \mathrm{d} h$ is elastic unloading contact stiffness (calculated from the slope of the tangent of the experimentally determined unloading curve); $L$ is load; $h$ is displacement; $\beta$ is geometry factor which takes the values $\beta=1$ for cone, 1.021 for Vickers, 1.034 for Berkovich; $A\left(h_{\mathrm{c}}\right)$ is the projected area of the contact (for perfectly sharp Vickers indenter $\left.A\left(h_{\mathrm{c}}\right)=24.5 \times h_{\mathrm{c}}^{2}\right) ; h_{\mathrm{c}}$ is contact depth.

The reduced modulus takes into account the fact that elastic displacements occur in both the specimen and the indenter. The elastic modulus of the specimen called the indentation modulus of elasticity, $E_{\mathrm{IT}}$, is given by:

$$
E_{\mathrm{IT}}=\frac{1-v^{2}}{\frac{1}{E_{\mathrm{r}}}-\frac{1-v_{\mathrm{i}}^{2}}{E_{\mathrm{i}}}},
$$

where $E_{\mathrm{i}}$ is the elastic modulus of the indenter (1141 GPa for diamond); $v, v_{\mathrm{i}}$ is the Poisson's ratio of the tested specimen and the indenter ( 0.07 for diamond), respectively.

The scratch test was performed using a CSM MCT adhesion tester with a Rockwell $\mathrm{C}$ diamond stylus with a tip radius of $0.2 \mathrm{~mm}$ at a load increasing from 0.01 to $30 \mathrm{~N}$ during 60 seconds. As a result of the scratch, test, the critical loads $L_{\mathrm{C} 1}$ and $L_{\mathrm{C} 2}$ were determined, corresponding to the cohesive and adhesive failures of the coatings, respectively.

\section{RESULTS AND DISCUSSION}

\section{A. Micro/nanostructure of the $n c-W C / a-C$ Coating}

Coating thickness measured from TEM micrographs was set as $1.8 \mu \mathrm{m}$ (Figure 1). It was found that the nc$\mathrm{WC} / \mathrm{a}-\mathrm{C}$ coating has a columnar morphology, characteristic for the zone " $\mathrm{T}$ " in Thornton's structure-zone model (SZM). ${ }^{[19,20]}$ The column diameter was estimated to be in the range of 10 to $200 \mathrm{~nm}$. It is known from literature that the columnar structure is often observed in the magnetron sputtered coatings. ${ }^{[21,22]}$

The different zones ( 1 to 3 and the $T$ one) in the SZM model are classified depending on process parameters (e.g., substrate temperature, gas pressure in the recipient, or ions' energy reaching the substrate surface). The substrate temperature is of great importance due to the fact that, if the homologous temperature $T_{\mathrm{s}} / T_{\mathrm{m}}$ (where $T_{\mathrm{s}}$ is the substrate temperature during coating deposition 

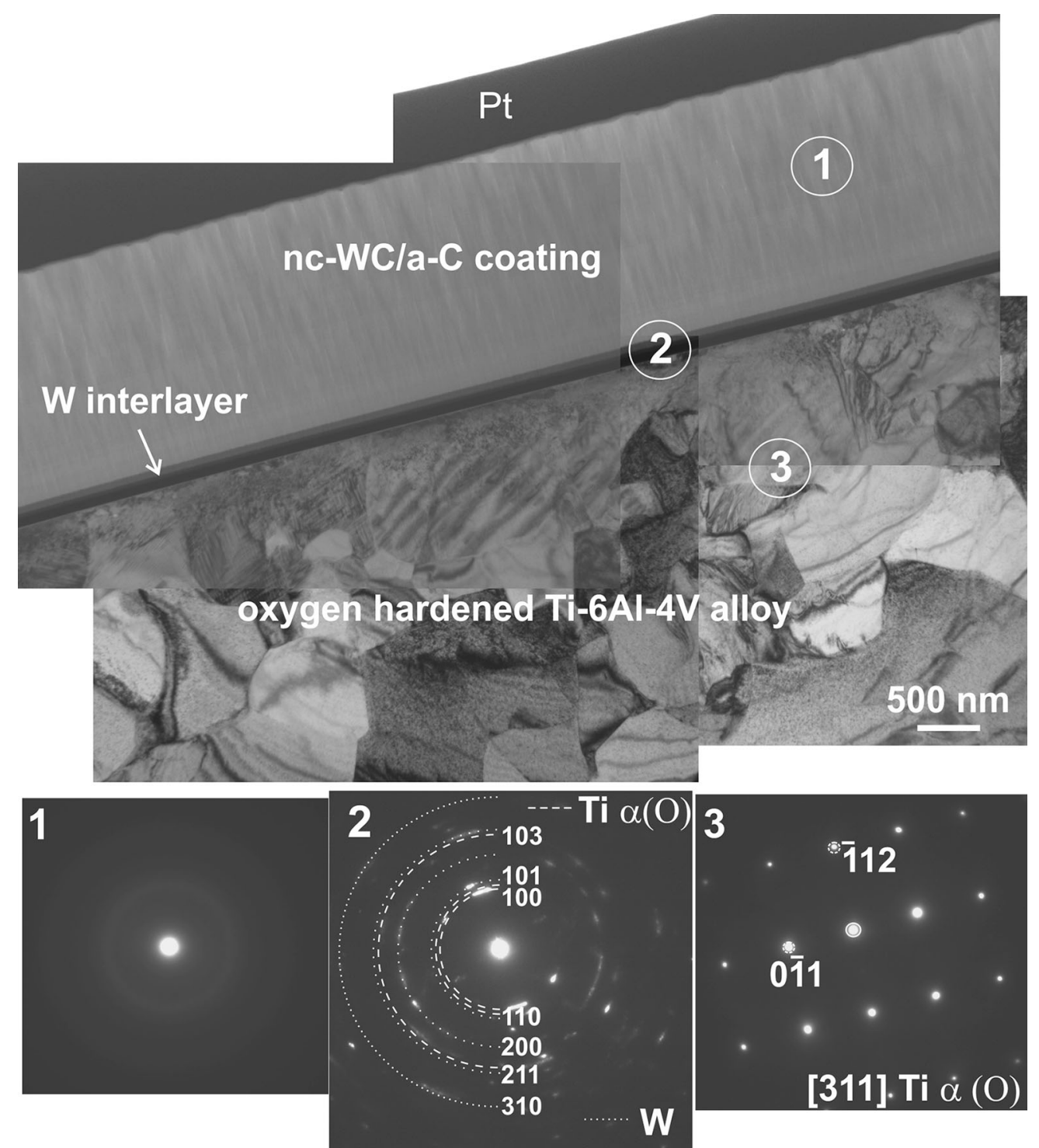

Fig. 1-Microstructure of the nc-WC/a-C coating on an oxygen-hardened Ti-6Al-4V alloy on top as well as SAED patterns below the image in a sequential order and their identification. TEM, cross-section FIB lamella.

and $T_{\mathrm{m}}$ means the melting point temperature of the coating material) is lower than 0.3 , the surface diffusion during deposition is negligible and the coating consists of columns of a 10 to $20 \mathrm{~nm}$ diameter, approximately, separated by voids of a few nanometers in diameter. The columns would have numerous defects and can be amorphous. ${ }^{[19,20]}$ In the present work, the homologous temperature during magnetron sputtering was approximately 0.1 , however the column diameter was distinctly greater than that expected from the SZM model.

The columnar structure of the similar coatings $(\mathrm{TiC} /$ a-C:H) was explained as a consequence of shadowing effects that occur during growth, originating from the $\mathrm{TiC}$ intermediate layer. ${ }^{[23]}$ It was reported in the literature that the boundary of the columns was rich in carbon. ${ }^{[23,24]}$

The electron diffraction patterns (SAEDs) taken from the coating were diffused and difficult to unequivocally interpret. Therefore, identification of the phases present in the coating was performed with use of the XRD, GIXRD as well as HRTEM techniques. The XRD and GIXRD patterns (Figure 2) show that different tungsten carbides are present in the coating: $\mathrm{W}_{2} \mathrm{C}$ (trigonal primitive; tp), $\mathrm{WC}_{0.98}$ (face-centered cubic; fcc), and $\mathrm{W}_{3} \mathrm{C}$ (cubic primitive; $\mathrm{cp}$ ). In addition, the presence of a $\beta$ - $\mathrm{WC}_{1-x}$ (fcc) carbide cannot be excluded. The size and spatial distribution of the carbide nanocrystallites in the coating were investigated with use of the HRTEM technique. It was found that the coating was composed of nanocrystallites of a size 2 to $5 \mathrm{~nm}$ embedded in an amorphous carbon matrix (Figures 3(a), (b)). The calculated diffraction patterns were obtained with use of the FFT. Analysis of the FFT patterns for particular nanocrystals confirmed the presence of different tungsten carbides in the coating, most frequently of $\mathrm{W}_{2} \mathrm{C}(\mathrm{tp})$ and, sporadically, of $\mathrm{WC}_{0.98}$ (fcc) as well as $\mathrm{W}_{3} \mathrm{C}$ (cp) ones. As an example, a FFT pattern from a $\mathrm{W}_{2} \mathrm{C}(\mathrm{tp})$ nanocrystal oriented along [234] the direction marked as 


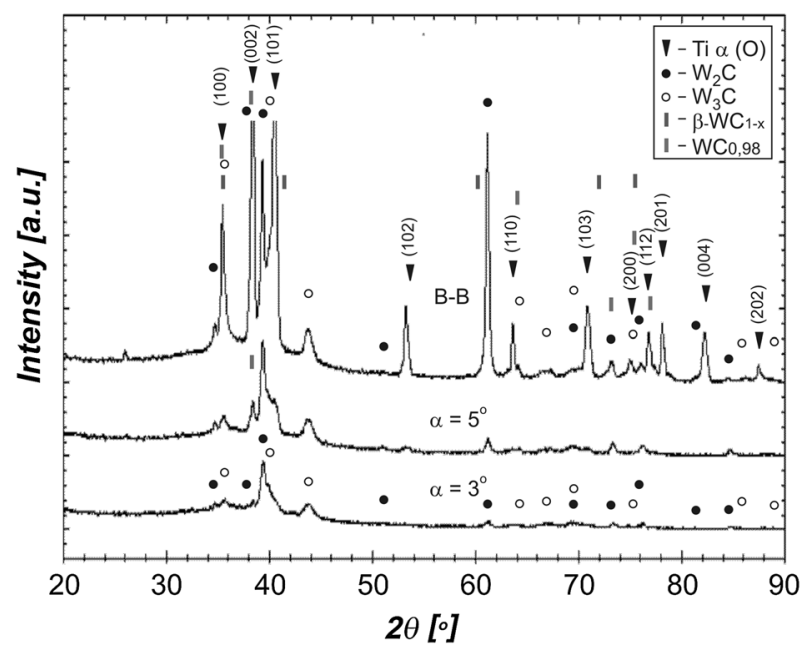

Fig. 2-Bragg-Brentano XRD (B-B) and GIXRD spectra at incidence angles $\alpha_{\mathrm{p}}=3 \mathrm{deg}$ and $\alpha_{\mathrm{p}}=5 \mathrm{deg}$ of the nc-WC/a-C coating on an oxygen-hardened Ti-6Al-4V alloy.
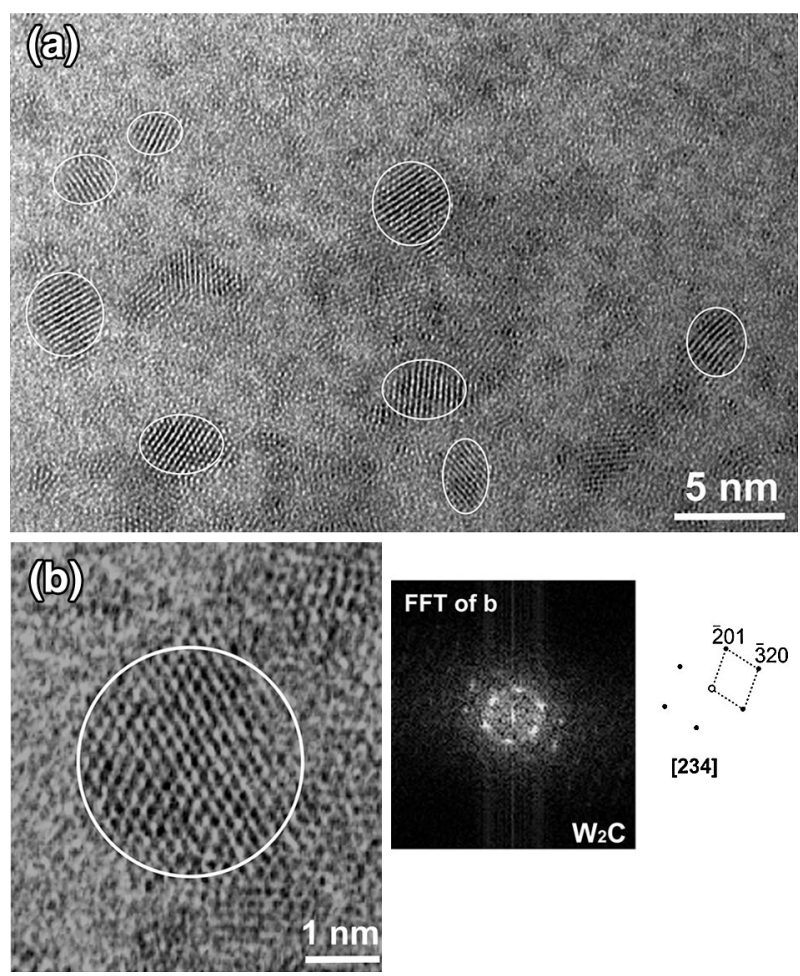

Fig. 3-HRTEM micrographs of the nc-WC/a-C coating deposited on an oxygen-hardened Ti-6Al-4V alloy. (a) General overview. (b) Fine particle and the corresponding FFT pattern and its identification.

A is presented in Figure 3(b). It was observed that the nanocrystallites were non-uniformly distributed in the coating. The neighboring nanocrystallites were separated by an amorphous carbon matrix at a distance not exceeding $12 \mathrm{~nm}$.

A 160-nm-thick graded interlayer was present between the nc-WC/a-C coating and the substrate material. Three sub-layers, 70, 30, and $60 \mathrm{~nm}$ thick (marked in Figure 4 as A1-A3, respectively) might be distinguished. Analysis
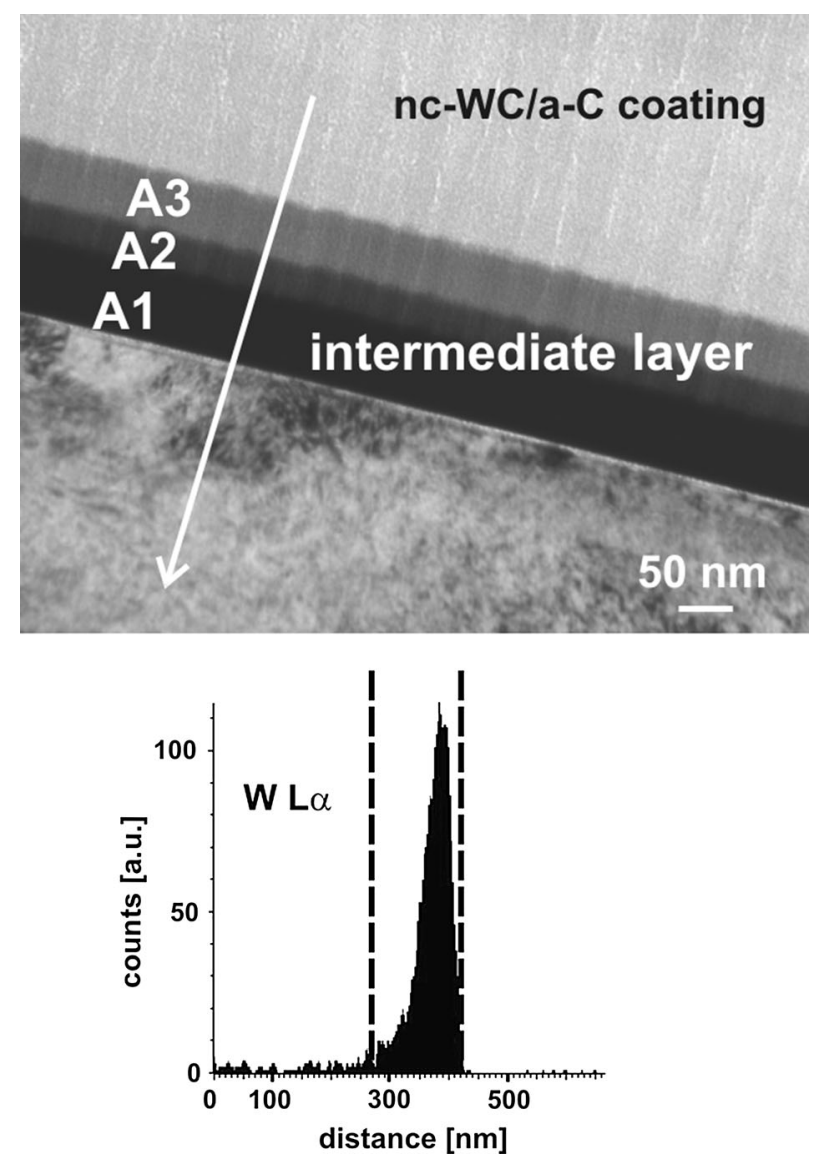

Fig. 4-Microstructure of a W-containing interlayer between the ncWC/a-C coating and an oxygen-hardened Ti-6Al-4V alloy, as well as a STEM-EDS line profile analysis of the $W$ distribution performed along a line marked in the micrograph. FIB lamella.

of the SAED pattern marked as 2 in Figure 1 revealed that the main crystalline component in this interlayer was $\mathrm{W}_{\alpha}$ (body-centered cubic; bcc). However, some rings indicating $\mathrm{WC}_{0.98}$ (fcc) and $\mathrm{W}_{2} \mathrm{C}(\mathrm{tp})$ were also found. The other component of these three sub-layers (visible in A1 to A3) was evidently an amorphous carbon. The STEM-EDS line profile microanalysis of the chemical composition confirmed a gradient concentration of $\mathrm{W}$ atoms in the interlayer, which decreased in the direction from the substrate to the coating surface (Figure 4). Contrary to that, the fraction of the amorphous carbon in the interlayer increased together with the distance from the substrate. In the substrate itself directly under the interlayer, a zone consisting of the $\operatorname{Ti} \alpha(\mathrm{O})$ phase was demonstrated (Figure 1) with grains of the size 0.2 to $1 \mu \mathrm{m}$. This zone was produced during a preliminary diffusion hardening of the near-to-surface zone of the specimens from the Ti-6Al-4V alloy at $1173 \mathrm{~K}\left(899.9^{\circ} \mathrm{C}\right)$ in a glow discharge plasma excited in the atmosphere $\mathrm{Ar}+\mathrm{O}_{2}$ before coating deposition.

\section{B. Micro/nanostructure of the $n c-T i C / a-C$ Coating}

Figure 5 shows a microstructure of the nc-TiC/a-C coating formed on an oxygen-hardened Ti-6Al-4V alloy, as well as the SAED patterns taken from the areas 
marked in the micrograph as 1 to 3 with their identification. SEM and TEM investigation of the nc-TiC/a-C coating cross-section showed that the coating was dense and of a uniform thickness of $3.3 \mu \mathrm{m}$ (Figure 5). Microstructural analysis revealed that the nc-TiC/a-C coating was composed of $\mathrm{TiC}_{x}$ nanocrystallites embedded in an amorphous carbon matrix. Similar to the previously described nc-WC/a-C one, this coating also has a columnar morphology. A columnar morphology of the magnetron sputtered nc-TiC/a-C coating was also observed by Shaha. ${ }^{[25]}$ With increasing intensity of the Ar ion impingement, brought about by increasing the frequency of pulsed DC sputtering, the coating microstructure changed from columnar to column-free. ${ }^{[26]}$
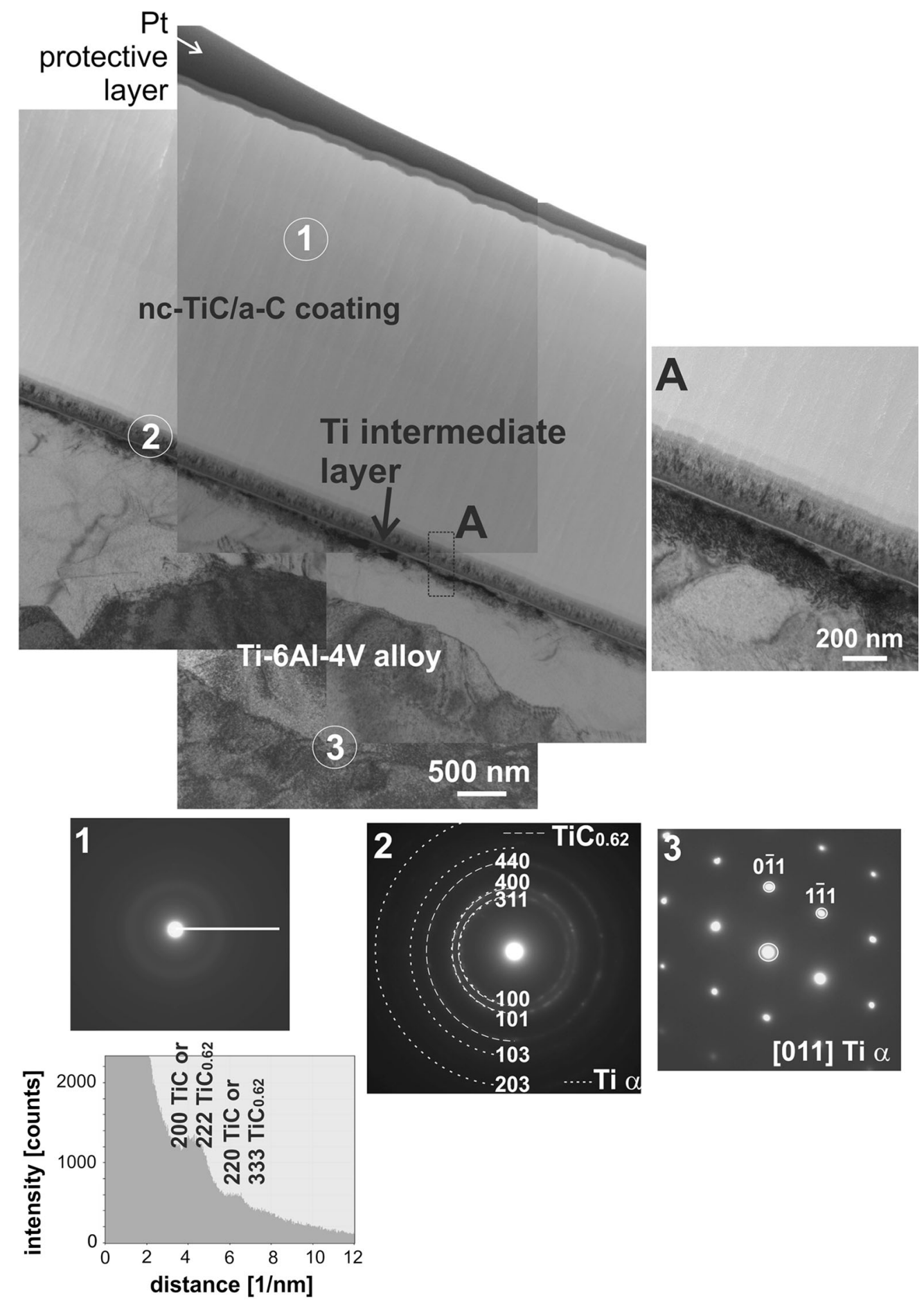

Fig. 5-Microstructure of the nc-TiC/a-C coating on an oxygen-hardened Ti-6Al-4V alloy on top as well as the SAED patterns below the image in a sequential order and their identification. An intensity profile along a line marked on the SAED pattern 1 is given as well. TEM, cross-section FIB lamella. 


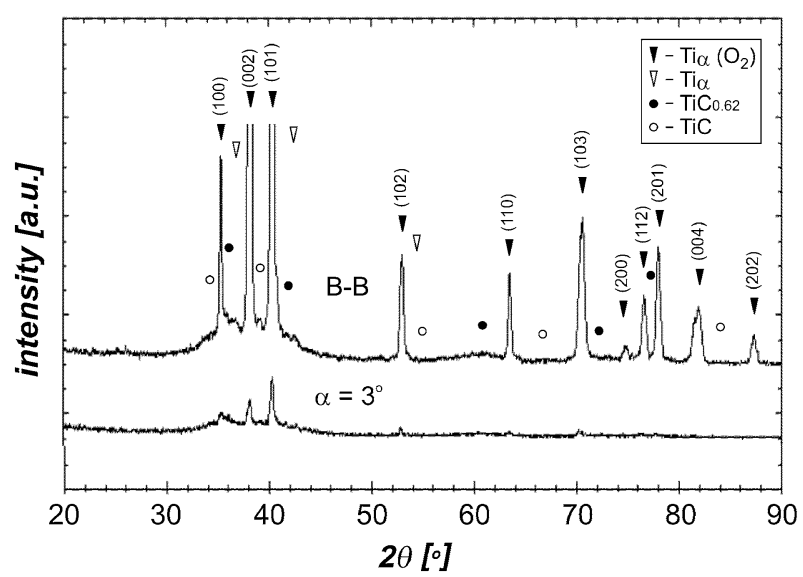

Fig. 6-XRD (B-B) and GIXRD spectra at the incidence angle $\alpha_{\mathrm{p}}=3 \mathrm{deg}$ of the nc-TiC/a-C coating on an oxygen-hardened Ti$6 \mathrm{Al}-4 \mathrm{~V}$ alloy.

Due to the high volume fraction of an amorphous carbon, the rings present in the SAED patterns taken from the coating are diffused and, therefore, difficult to unequivocally identify. However, a series of rings corresponding to plausibly different interplanar distances of $\mathrm{TiC}$ and $\mathrm{TiC}_{0.62}$ phases (both of them facecentered cubic; fcc) are visible in the electron diffraction pattern intensity profile of the coating (Figure 5, diffraction pattern no. 1, top right corner). Similar findings were observed in our earlier work on a thin $(\sim 500 \mathrm{~nm})$ nc-TiC/a-C coating. ${ }^{[3]}$

The phase composition of the coating was also investigated using XRD, GIXRD, and HRTEM. The diffraction peaks on XRD and GIXRD spectra correspond to $\mathrm{TiC}$ (fcc) and $\mathrm{TiC}_{0.62}$ (fcc) phases (Figure 6).

As shown in Figure 5, a 200-nm-thick graded interlayer formed between the nanocomposite coating and the substrate. This interlayer was produced in order to increase adhesion of the coating to the underlying bulk material. Two phases - $\mathrm{Ti} \alpha$ (hcp) and $\mathrm{TiC}_{0.62}$ (fcc) were identified in the interlayer by the SAED method (Figure 5, electron diffraction no. 2). The size of the nanocrystallites of both phases in the interlayer evaluated from the dark-field TEM images was estimated in the range 10 to $70 \mathrm{~nm}$. In contrast, it was found from the HRTEM images of the top nc-TiC/a-C coating (Figure 7(a)) that the size of the nanocrystallites embedded in an amorphous matrix was in the range 1 to $3 \mathrm{~nm}$. With use of the FFT (Figure 7(a)), the nanocrystallites embedded in the carbon matrix of the coating were identified as $\mathrm{TiC}_{0.62}$ and $\mathrm{TiC}$ phases. The distance between the nanocrystallites varied from 2 to $15 \mathrm{~nm}$. On the other hand, the $\mathrm{Ti} \alpha$ and $\mathrm{TiC}_{0.62}$ nanocrystallites of a size up to $25 \mathrm{~nm}$ were found at the interface between the nc-TiC/a-C coating and the interlayer (Figure 7(b)).

\section{Quantitative Metallography}

Quantitative metallography was carried out to quantify coating microstructure. The following parameters
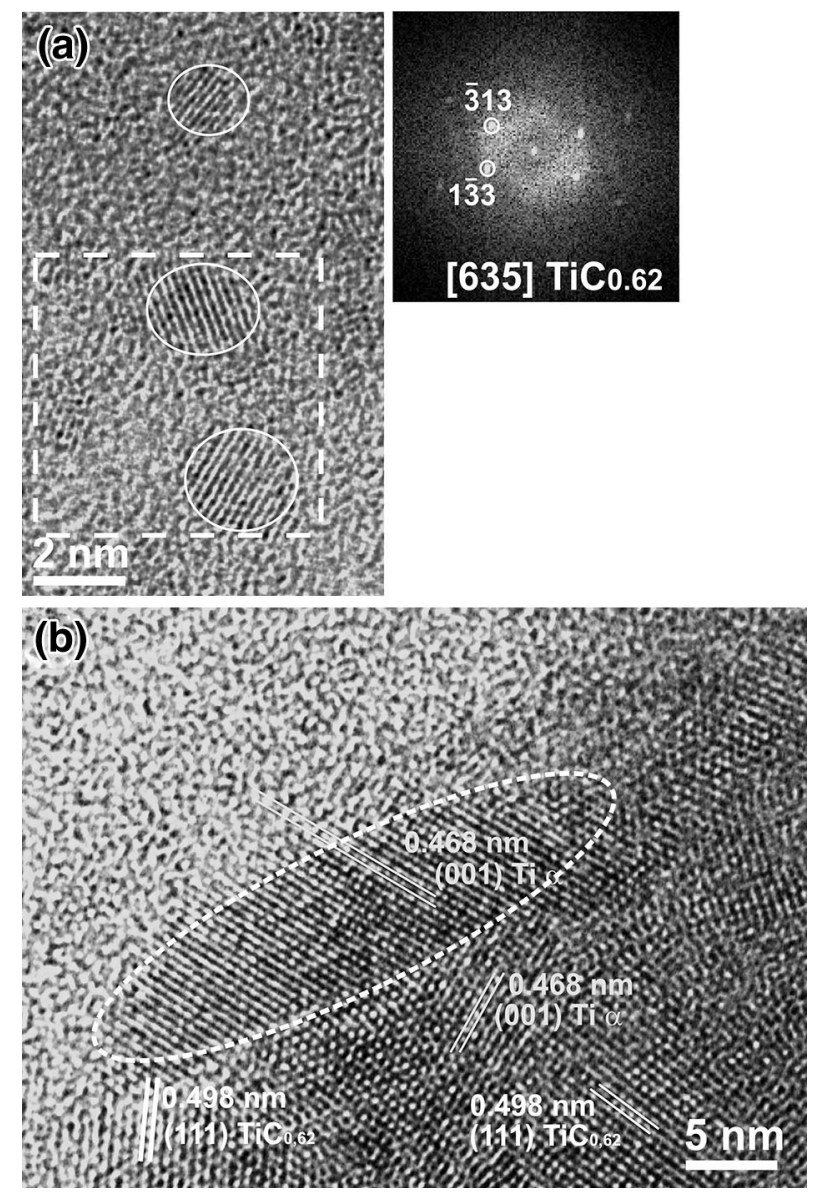

Fig. 7-(a) HRTEM micrograph of the nc-TiC/a-C coating and a corresponding FFT pattern calculated from the area marked as a square in the micrograph and its identification, $(b)$ HRTEM micrograph of the interlayer.

were determined: particles' equivalent circle diameter $\left(\right.$ ECD), mean diameter $(d)$, particle projection area $A_{\mathrm{A}}$ (particle part of the projection area), and the volume fraction $V_{\mathrm{V}}$. In order to gain representative results, 77 and 90 nanoparticles revealed by HRTEM were analyzed for the nc-TiC/a-C and nc-WC/a-C coatings, respectively. The volume fraction of the nanoparticles was estimated according to a procedure described in detail by Wosik et al. ${ }^{[27]}$ Table I contains the statistical characteristics of the nanocrystalline particles embedded in amorphous carbon matrices of both the nc-WC/a-C and nc-TiC/a-C nanocomposite coatings. Distribution of the nanocrystallites' size (ECD) for the nc-WC/a-C and nc-TiC/a-C coatings is given in Figures 8(a) and (b), respectively.

\section{Tribological Properties}

The tribological properties of the coatings were investigated in sliding contact with the ball in two modes - at a constant load in rotation and at a progressive load in translational motion. The effect of the load on the friction coefficient and the load-bearing capacity in contact load conditions of a coating/substrate system were studied during sliding of an 
Table I. Statistical Characteristics of the Nanocrystalline Particles Embedded in an Amorphous Carbon Matrix of the nc-WC/a-C and nc-TiC/a-C Nanocomposite Coatings

\begin{tabular}{lccccc}
\hline Coating & Number of Analyzed Particles & ECD $(\mathrm{nm})$ & $d(\mathrm{~nm})$ & $A_{\mathrm{A}}(\mathrm{pct})$ & $V_{\mathrm{v}}(\mathrm{pct})$ \\
\hline nc-WC/a-C & 90 & 2.3 & 2.6 & 33.8 & 13 \\
nc-TiC/a-C & 77 & 1.7 & 1.8 & 12.3 & 3 \\
\hline
\end{tabular}

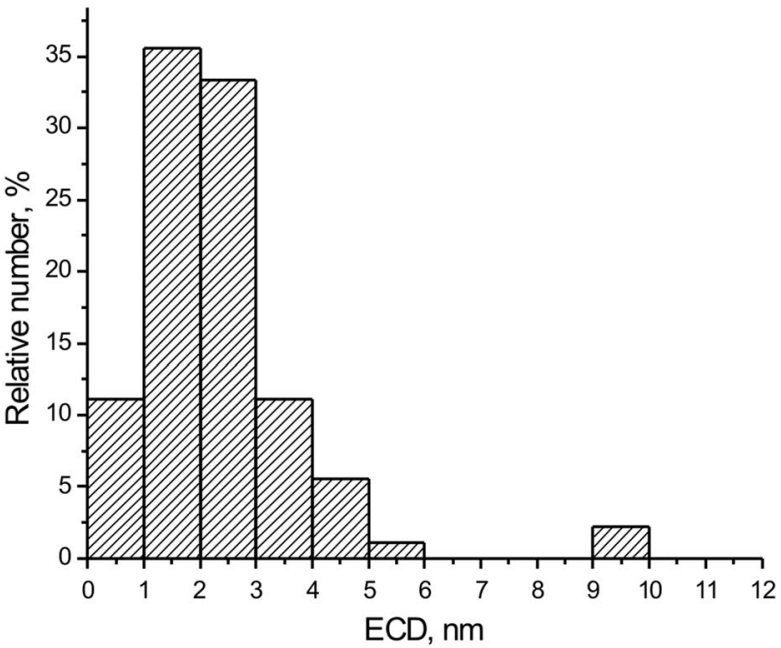

(a)

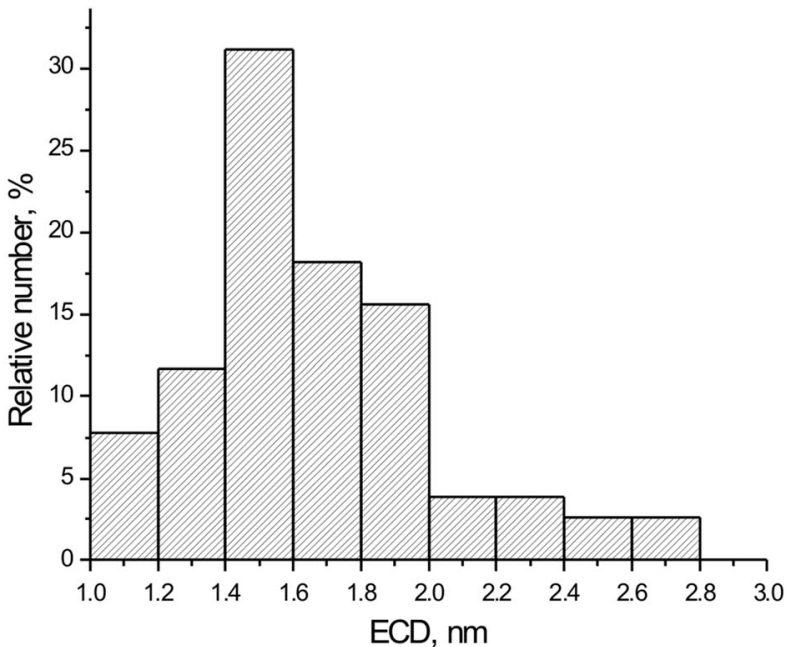

(b)

Fig. 8-Nanocrystallites' size distribution in the $(a)$ nc-WC/a-C and $(b)$ nc-TiC/a-C coatings.

$\mathrm{Al}_{2} \mathrm{O}_{3}$ ball of $6 \mathrm{~mm}$ diameter under a load in the range of 0 to $30 \mathrm{~N}$. Microscopic observation of the wear tracks in translational motion revealed neither cracks nor delamination of the coatings, even at $30 \mathrm{~N}$. Independently, a stable and uniform friction without cracking or delamination was confirmed by the low and invariable value of acoustic emission (Figure 9). Pressing of the rigid ceramic ball into the coating under the load in the range 0 to $25 \mathrm{~N}$ caused an elastic deformation only of the coating/substrate system, as evidenced by the lack of a groove in the wear track. The residual depth $R_{\mathrm{d}}$ measured after unloading, corresponding to the load of $25 \mathrm{~N}$, reached an average value of $0.03 \mu \mathrm{m}$ for the nc$\mathrm{WC} / \mathrm{a}-\mathrm{C}$ coating and $0.04 \mu \mathrm{m}$ for the $\mathrm{nc}-\mathrm{TiC} / \mathrm{a}-\mathrm{C}$ one. After exceeding the value of $25 \mathrm{~N}$, the residual depth $R_{\mathrm{d}}$ reached at most 0.04 and $0.12 \mu \mathrm{m}$ for the coatings with WC and TiC nanocrystallites, respectively (Figure 9).

The analysis of stresses and strains in the contact load conditions of the coating/substrate systems is often carried out with the application of Hertz's theory, which is extended for such systems ${ }^{[28]}$ or forms the basis of FEM modeling. ${ }^{[29]}$ According to the basic assumption of Hertz's theory, the calculations must be carried out in the elastic range. For this reason, in the contact of the ceramic ball with the coating under consideration, at first a mean value of the contact pressure was determined and then it was compared with the yield stress for the systems.

In this paper, the mean value of the contact pressure $\left(p_{\mathrm{m}}\right)$ at the given load (assuming the stationary contact of the ball with the plane at the given moment) was designated in accordance with Hertz's theory as ${ }^{[30]}$.

$$
p_{\mathrm{m}}=\frac{F}{\pi a^{2}}
$$

and

$$
a^{3}=\frac{3 F R}{4 E^{*}},
$$

where $p_{\mathrm{m}}$ is mean contact pressure, $a$ is contact radius, $R$ is radius of the ball, $F$ is load, $E^{*}$ is composite (reduced) elastic modulus of the bodies in contact $1 /$ $E^{*}=\left(1-v^{2}\right) / E+\left(1-v_{1}^{2}\right) / E_{1}$, where $E, E_{1}$, and $v, v_{1}$ are elastic modulus and Poisson's ratio of the plane and the ball, respectively.

The mean value of the contact pressure determined for the loads from 1 to $30 \mathrm{~N}$ changed in the range of 0.46 to $1.43 \mathrm{GPa}$ for the system with the nc-WC/a-C coating and 0.37 to $1.14 \mathrm{GPa}$ for the nc-TiC/a-C one. Plastic deformation can occur when the contact pressure is greater than the yield stress $Y$ in accordance with the relationship, $p_{\mathrm{m}}>1.1 Y^{[30-33]}$ If $p_{\mathrm{m}}$ is in the range $1.1 Y<p_{\mathrm{m}}<3 Y$ the yield stress can be dependent on the hardness $(H)$, and for greater loads the $H / Y$ ratio receives a relatively constant value equal to 3 .

The analysis of the deformation of the coating/ substrate system in contact with the $\mathrm{Al}_{2} \mathrm{O}_{3}$ ball of a $6 \mathrm{~mm}$ diameter shows that the maximum load of $30 \mathrm{~N}$ used in the tests does not cause plastic deformation, 


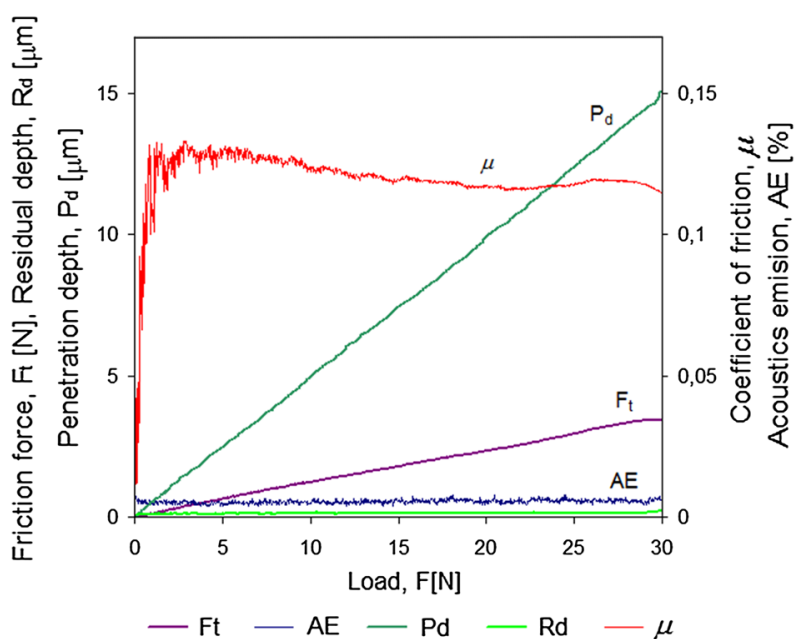

(a)

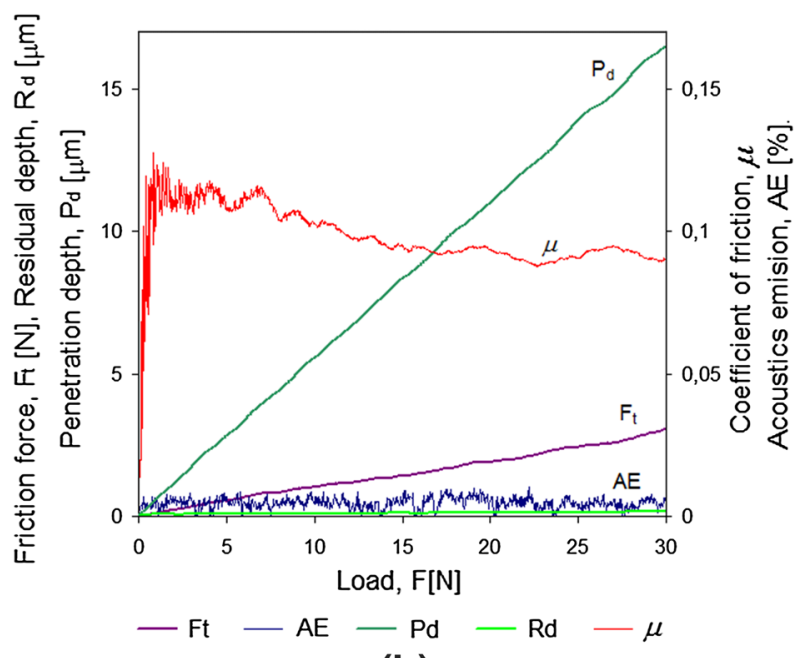

(b)

Fig. 9-The resistance to motion and deformation of the $(a)$ nc-WC/ $\mathrm{a}-\mathrm{C}$ and $(b)$ nc-TiC/a-C coatings deposited on an oxygen-hardened Ti-6Al-4V alloy measured during sliding against the alumina ball under increasing load.

while the mean contact pressure $p_{\mathrm{m}}$ corresponding to the applied load is less than $Y=4.7 \mathrm{GPa}$ for nc-WC/a-C and $Y=3.4 \mathrm{GPa}$ for nc-TiC/a-C coatings. This state of deformation will also be retained when the mean contact pressure is twofold greater, which corresponds to the load distributed only on half of the maximum contact area of the ball $\left(\pi a^{2} / 2\right)$ sliding on a flat surface.

The COF $(\mu)$ in sliding contact is generally composed of two parts: an adhesive component, which is dependent on the shear strength of the interface $(S)$, and the deformation component, also called the plowing term:

$$
\mu=\frac{F_{\mathrm{F}}}{F}=\frac{A \cdot S}{F}+\frac{F_{\mathrm{p}}}{F},
$$

where $F_{\mathrm{F}}$ is friction force, $A$ is area of the contact, $S$ is shear strength of the interface, and $F_{\mathrm{p}}$ is plowing term, $F$ is applied normal load to the ball.

The shear strength $S$ at a high pressure depends on the material parameters $S_{0}$ and $\alpha$, which represent material properties controlling friction and can be described approximately as, $S=S_{0}+\alpha p_{\mathrm{m}} \cdot{ }^{[34]}$ The friction coefficient can be reduced when the area of contact, the shear strength, and the plowing contribution are minimized.

The values of these components depend on many factors, mostly on the load-carrying ability of the tribological contact. This is of particular importance during friction of the coating/substrate systems when exceeding the critical load at a contact point is conducive to cracking of the coating and to subsequent delamination of the coating. Below the elastic limit and, for a relatively thin coating, the plowing component can be omitted, and the friction coefficient is determined by the shear strength of the interface and the area of contact.

The friction tests showed a decrease in the COF during an increase in the load, particularly for the loads greater than $1 \mathrm{~N}$ (Figure 9). The change of $\mathrm{COF}$ in the initial period below $1 \mathrm{~N}$ was the result of contact formation and the resistance to motion depended on the real surface roughness, which was not perfectly smooth. Hence, the results are shown only for the range of 1 to $30 \mathrm{~N}$. The nc-TiC/a-C coating has a lower friction in comparison with the nc-WC/a-C one, which is due to the higher volume fraction of a lubricating amorphous carbon phase in the nc-TiC/a-C coating than in the coating with the WC nanocrystallites. Due to the lower hardness and stiffness of the nc-TiC/a-C coating, it will have a lower shear strength too.

The decrease in the COF with the load increase can be explained by the Hertzian contact model, which has been previously used for analyzing friction of other solid lubricant coatings. ${ }^{[34,35]}$ The COF for a smooth and rigid ball in sliding contact with a flat element with a perfectly smooth surface in the range of elastic deformation can be calculated with the formula:

$$
\mu=S_{0} \pi\left(\frac{3 R}{4 E^{*}}\right)^{2 / 3} F^{-1 / 3}+\alpha
$$

where $S_{0}$ is interfacial shear strength between the ball surface and the underlying wear track, $R$ is radius of the ball, $E^{*}$ is composite elastic modulus of the bodies in contact, $\alpha$ represents the pressure dependence of the shear strength.

The change in the value of the friction coefficient is distinct from 0.13 to 0.09 , but its range is small, due to the specific nature of co-operation in such a test, where the ball under progressive loading is in contact with the coating only once on the path friction (Figure 10). Over the load of $25 \mathrm{~N}$ the friction coefficient increased to a very low extent. Hard carbide particles strengthen the structure of the composite but may also disturb the friction process and, in extreme cases, may cause a big stress concentration. Tested coatings belong to the group of so-called solid lubricants and their low-friction properties are time-dependent, as confirmed in the friction tests under a constant load during a long time (Figure 11).

Comparison of the tribological properties of the investigated coatings possessing different thicknesses is 


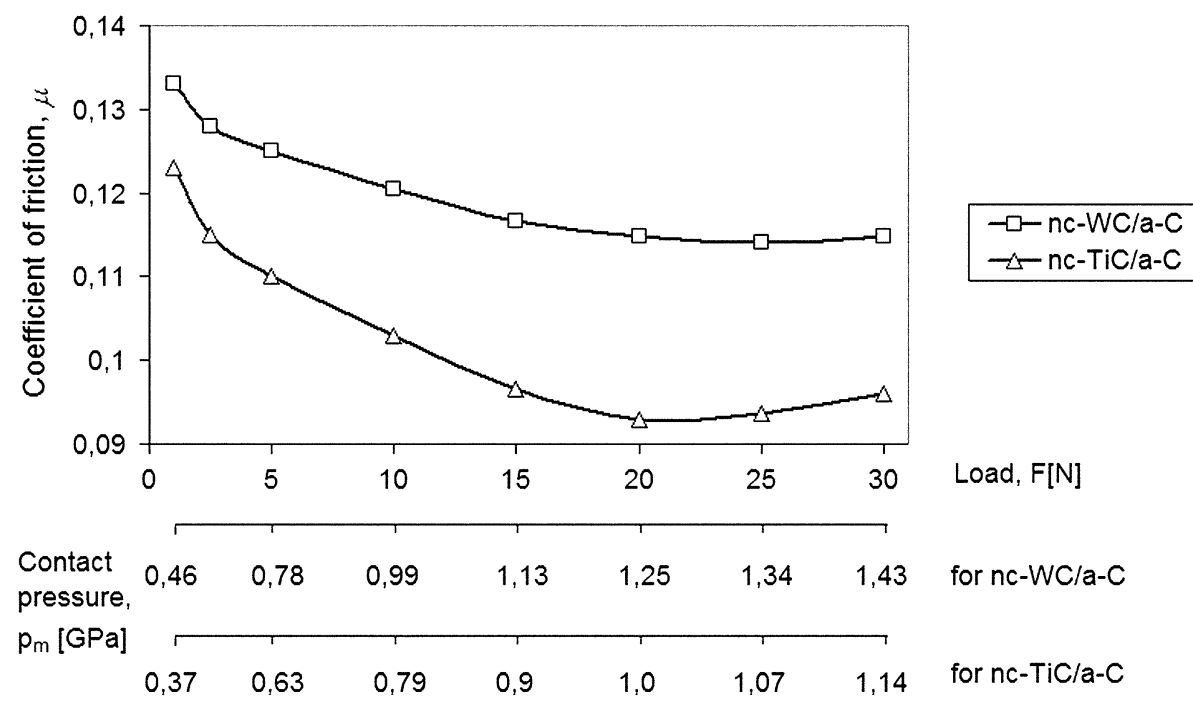

Fig. 10-Effect of the load on friction coefficient for the nc-WC/a-C and nc-TiC/a-C coatings.

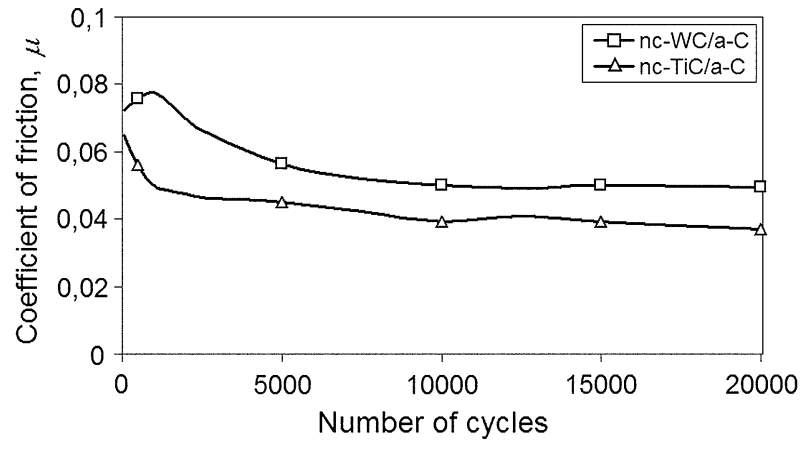

Fig. 11-Dry friction coefficient of the nc-TiC/a-C and nc-WC/a-C coatings during sliding against the alumina ball.

possible because they are relatively thick and deposited on a substrate with a hardness and elastic modulus comparable to the coating. Hence, an oxygen-hardened alloy provides strong support for the coatings and creates a uniform coating/substrate system.

The friction processes for both coatings in dry sliding contact with the alumina ball at a constant load were stable and ran in a similar way. The greatest changes in friction force were observed in the initial period of the sliding friction, which was related to the matching of the contact surfaces. The average value of the initial $\mathrm{COF}$ was equal to 0.07 for the $\mathrm{nc}-\mathrm{WC} / \mathrm{a}-\mathrm{C}$ and 0.06 for the nc$\mathrm{TiC} / \mathrm{a}-\mathrm{C}$-coated alloy (Figure 11). Then the friction force slightly decreased with time until a constant value was reached. The COF values in the steady-state period were approximately 0.05 for the $\mathrm{nc}-\mathrm{WC} / \mathrm{a}-\mathrm{C}$ coating and slightly less (0.04) for the nc-TiC/a-C one. This low resistance to motion, as well as its decrease as a function of time, was due to the formation of a carbonaceous third body material during friction. As a result, a selflubricating film was formed on the counter-face (i.e., on the ceramic $\mathrm{Al}_{2} \mathrm{O}_{3}$ ball) in the contact zone, which enabled the easy shear of the sliding couple and
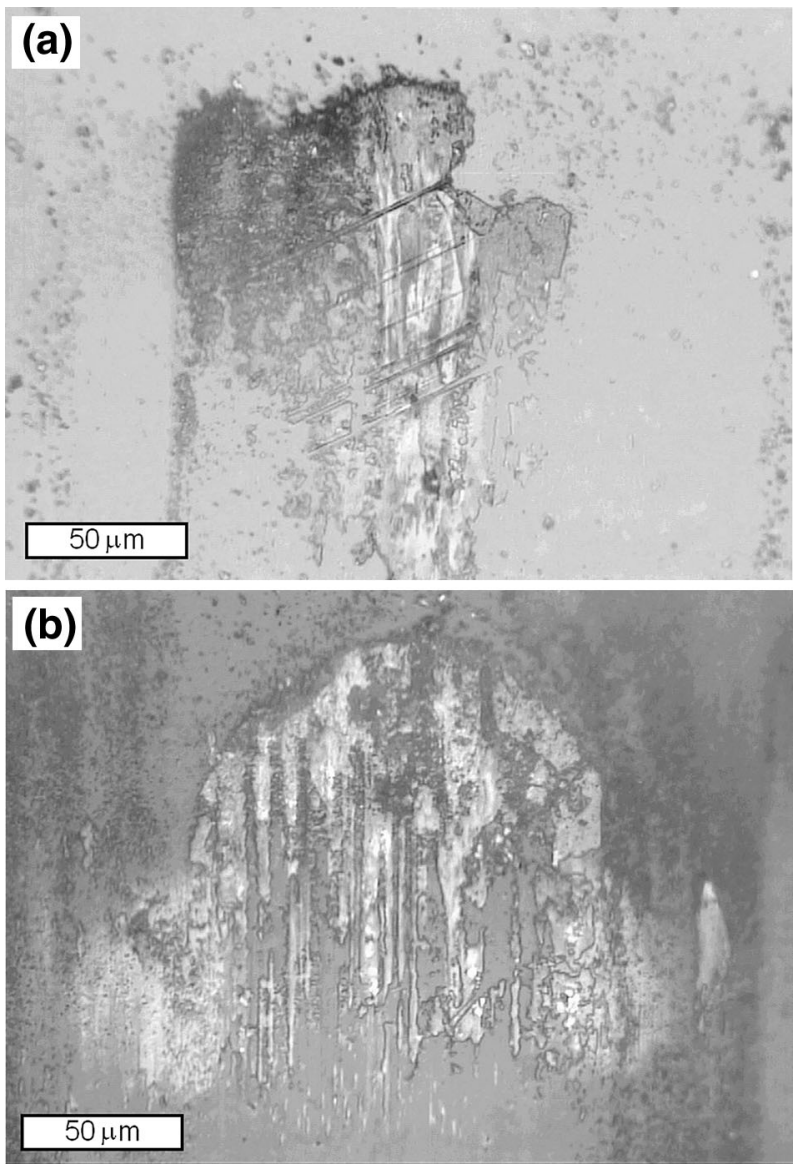

Fig. 12-LM micrographs of scars on the surface of a counter-body (alumina ball) formed during sliding against the $(a)$ nc-WC/a-C or (b) nc-TiC/a-C coating.

protected the surfaces from destruction (Figure 12). This film is assumed to be composed mainly of graphitelike carbon atom clusters. ${ }^{4,5,7]}$ The rate of the 
self-lubricating film formation was greater for the nc-TiC/a-C coating as a result of a greater volume fraction of the amorphous a-C carbon matrix in the coating. Due to that, as well as to a lower hardness of the coating, the contact area during dry friction of this coating underwent faster and easier matching. The lubricating film separated the surface of the ceramic ball from that of the nanocomposite coating and effectively decreased the resistance to motion. It is worth mentioning that, due to the low friction as well as to a low load applied to the ball which did not bring about the plastic deformation of the coating, the deformation component of the friction force was very small. The calculated value of the Hertzian contact pressure at the beginning of each sliding test was in the range of 0.5 to $0.62 \mathrm{GPa}$.

The wear mechanism of the nanocomposite coatings with an amorphous carbon a-C matrix is frequently explained in the literature in terms of the graphitization process. ${ }^{[4,35-37]}$ This process occurs due to transformation of the $\mathrm{sp}^{3}$-bonded carbon to the $\mathrm{sp}^{2}$-bonded one. The latter is characteristic of a graphite-like hexagonal structure with superior sliding properties, however, of a smaller strength. The process of sliding friction provides the energy required for the transformation of the diamond-like to graphite-like carbon under thermal and strain effects from the repeated friction cycles. ${ }^{[36]}$

In sliding contact with the $\mathrm{Al}_{2} \mathrm{O}_{3}$ ball, the wear of both composite coatings was mainly of a micro-abrasive and adhesive nature with no significant wear of the ball surface. Adhesive wear occurred after the formation of the self-lubricating film and may be due to the transfer of this film to the counter-face and back to the wear track, which was also observed by other researchers. ${ }^{[36]}$ The occurrence of hard particles in the contact zone disturbed the steady-state sliding process with lubrication by the graphite-like film and intensified the abra-

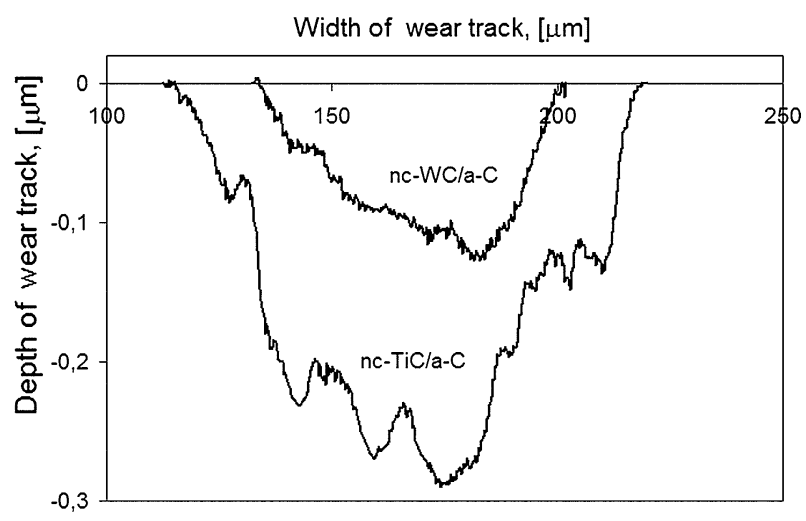

Fig. 13-Profiles of the grooves in the nc-TiC/a-C and nc-WC/a-C coatings after 20,000 cycles in dry sliding contact. sion. The different mixtures of the carbides $\mathrm{W}_{2} \mathrm{C}$, $\mathrm{WC}_{0.98}$, and $\mathrm{W}_{3} \mathrm{C}$ in the nc-WC/a-C coating and $\mathrm{TiC}_{0.62}$ and $\mathrm{TiC}$ ones in the nc-TiC/a-C coating could bring about changes in the sliding condition due to different crystallographic structures of different phases. As a result, distinct scratches along the sliding direction and the wear debris at the edges of grooves, characteristic of abrasive wear, were observed in the wear tracks. The cross-sectional profiles of the grooves formed in the coatings by the ball are shown in Figure 13. The absence of pile-ups at the grooves' edges gives evidence of elastic deformations only in the contact zone. Suitable loadbearing capacity of the coating/substrate system was provided by a particular duplex treatment which ensured an increase of the coating lifetime on the hardened substrate in comparison with the one on a baseline substrate and protected against severe wear. ${ }^{[2,38]}$ The profile of the wear groove in the nc$\mathrm{TiC} / \mathrm{a}-\mathrm{C}$ coating was more irregular than that in the nc$\mathrm{WC} / \mathrm{a}-\mathrm{C}$ one. The greater roughness of the worn surface was due to a greater number of scratches formed as a result of the micro-abrasion of the softer coating by the hard carbides. The wear resistance of the a-C matrix without reinforcing particles was significantly lower in comparison with the composite coatings with WC and $\mathrm{TiC}$ nanocrystallites. It is worth noticing that the wear of the a-C coating during friction was caused by their abrasion and delamination as shown in the previous studies.

During the scratch test, the first cohesive cracks occurred when the load $L_{\mathrm{C} 1}$ achieved the value of 5 and $7.5 \mathrm{~N}$ for the nc-WC/a-C and nc-TiC/a-C coatings, respectively, whereas the adhesive cracks were observed at the critical load $L_{\mathrm{C} 2}$ equal to 12 or $13 \mathrm{~N}$ for the nc$\mathrm{WC} / \mathrm{a}-\mathrm{C}$ or nc-TiC/a-C coatings, respectively (Table II). Even though the resistance to scratching was rather low, the coatings exhibited a good wear resistance during sliding friction. The wear rate $\left(W_{\mathrm{V}}\right)$ of the nc-WC/a-C coating was equal to $0.08 \times 10^{-6} \mathrm{~mm}^{3} \mathrm{~N}^{-1} \mathrm{~m}^{-1}$, whereas for the nc-TiC/a-C one it was almost four times higher $\left(0.28 \times 10^{-6} \mathrm{~mm}^{3} \mathrm{~N}^{-1} \mathrm{~m}^{-1}\right)$, even though the COF values of both coatings were close to each other. This behavior can be explained in part by the lower hardness of the nc-TiC/a-C coating, as well as by the lower volume fraction of the titanium carbides in this coating (merely 3 pct), which did not strengthen their structure enough. In contrast to that, the wear resistance of the coating with tungsten carbides nanocrystallites was much greater, plausibly due to its greater elasticity (Figure 9). The elastic strain to failure, which is related to the ratio of hardness $(H)$ and elastic modulus $(E)$, has been shown by a number of authors to be a more suitable parameter for predicting a coating's resistance to wear than its hardness alone. ${ }^{[39-41]}$ The high values of

Table II. Mechanical and Tribological Characteristics of the nc-WC/a-C and nc-TiC/a-C Coatings Deposited on OxygenHardened Ti-6Al-4V Alloy Substrates (COF Values Measured During the Steady-State Sliding)

\begin{tabular}{lccccccrr}
\hline Coating & $H_{\mathrm{IT}}(\mathrm{GPa})$ & $E_{\mathrm{IT}}(\mathrm{GPa})$ & $H / E$ & $H^{3} / E^{2}(\mathrm{GPa})$ & $L_{\mathrm{C} 1}(\mathrm{~N})$ & $L_{\mathrm{C} 2}(\mathrm{~N})$ & $W_{\mathrm{v}} \times 10^{-6}\left(\mathrm{~mm}^{3} \mathrm{~N}^{-1} \mathrm{~m}^{-1}\right)$ & $\mathrm{COF}$ \\
\hline nc-WC/a-C & 14.3 & 176 & 0.08 & 0.094 & 4.9 & 12.4 & 0.08 \\
nc-TiC/a-C & 10.1 & 110 & 0.09 & 0.085 & 7.5 & 13.4 & 0.05 \\
\hline
\end{tabular}



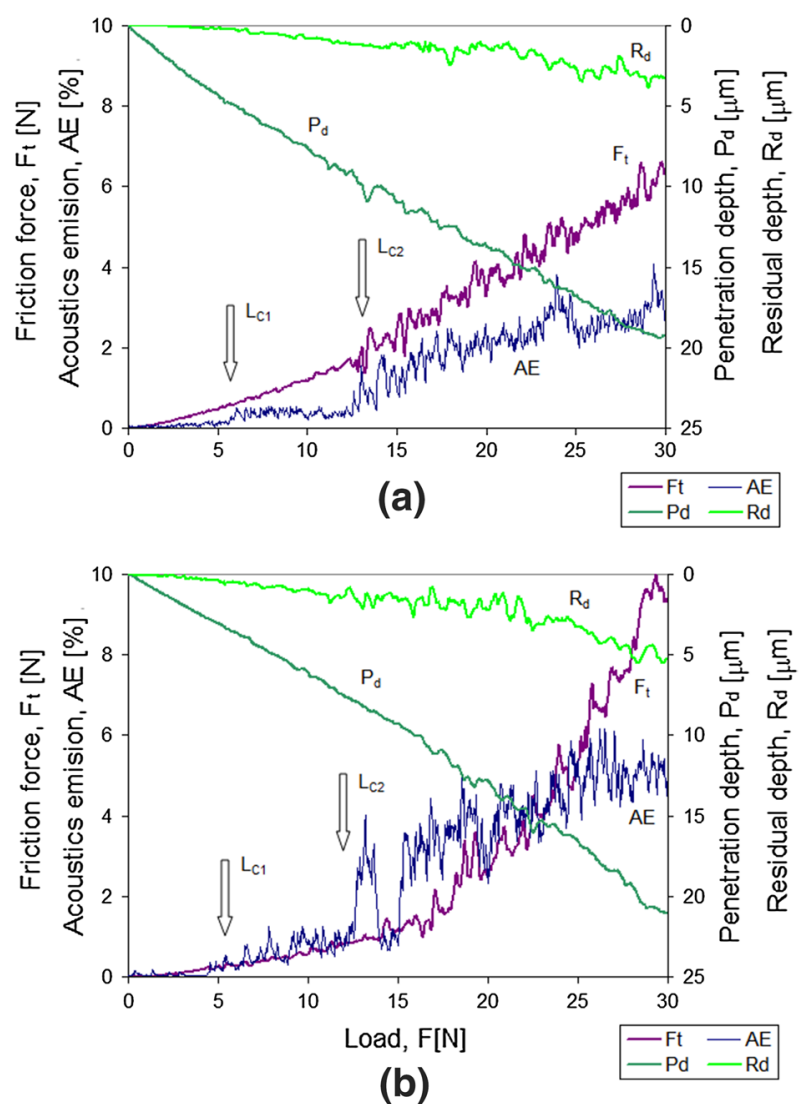

Fig. $14-$ Results of the scratch tests for the $(a)$ nc-WC/a-C and $(b)$ nc-TiC/a-C coatings deposited on an oxygen-hardened Ti-6Al-4V alloy.

the $H / E$ ratio, above 0.1 , result in high wear resistance as reported by Pei et al. ${ }^{[41]}$ Additionally, the $H^{3} / E^{2}$ ratio should be a strong indicator of a coating's resistance to plastic deformation in this type of contact loading. The value of the $H^{3} / E^{2}$ ratio for the $\mathrm{nc}-\mathrm{WC} / \mathrm{a}-\mathrm{C}$ coating is close to 0.1 and is higher than nc-TiC/a-C one, what results in the higher resistance to plastic deformation of the nc-WC/a-C coating as well as its higher wear resistance. The ratio $\left(R_{\mathrm{d}} / P_{\mathrm{d}}\right)$ of the residual depth $R_{\mathrm{d}}$ to the penetration depth $P_{\mathrm{d}}$ obtained from the scratch test was 0.16 for the specimen with the nc-WC/a-C coating and was approximately twice smaller $(0.29)$ than that for the specimen with the nc-TiC/a-C one (Figure 14). This result was due to a higher volume fraction of tungsten carbide nanocrystallites, which increased the load-bearing capacity and rigidity of the nc-WC/a-C coating. Additionally, the crack propagation in this coating is more difficult, what is reflected in the reduced plastic deformation during the hardness measurement.

\section{CONCLUSIONS}

Micro/nanostructure and tribological properties of the nanocomposite nc-WC/a-C and nc-TiC/a-C coatings deposited on an oxygen-hardened Ti-6Al-4V alloy by DC magnetron sputtering were examined. It was found that both nanocomposite coatings were composed of different carbide nanocrystallites (few nanometers sized) embedded in an amorphous carbon matrix.

The 1.8- $\mu$ m-thick nc-WC/a-C coating was composed of the $\mathrm{W}_{2} \mathrm{C}$ (tp), $\mathrm{WC}_{0.98}$ (fcc) and $\mathrm{W}_{3} \mathrm{C}$ (cp) phases (size of 2 to $5 \mathrm{~nm}$ ). A 160-nm-thick graded interlayer between the nc-WC/a-C coating and the underlying substrate consisted of $\mathrm{W}_{\alpha}$ (bcc), $\mathrm{W}_{2} \mathrm{C}$ (tp), and $\mathrm{WC}_{0.98}$ (fcc) nanocrystallites and an amorphous carbon. The nc-TiC/ a-C coating was 3.3- $\mu$ m-thick and consisted of 1 to $3 \mathrm{~nm}$ $\mathrm{TiC}$ (fcc) and $\mathrm{TiC}_{0.62}$ (fcc) nanocrystallites embedded in the amorphous carbon matrix. A 200-nm-thick graded interlayer consisting of a mixture of $\mathrm{Ti} \alpha$ (hcp) and $\mathrm{TiC}_{0.62}$ (fcc) nanocrystallites was formed between the coating and the oxygen-hardened Ti-6Al-4V substrate.

The HRTEM analysis indicated that the volume fraction of tungsten carbides in the nc-WC/a-C coating was equal to $13 \mathrm{pct}$, whereas in the $\mathrm{nc}-\mathrm{TiC} / \mathrm{a}-\mathrm{C}$ one the volume fraction of the titanium carbides was equal to just 3 pet.

The hardness of both coatings (10 to $14 \mathrm{GPa}$ ) and their scratch resistance were low. In contrast, their tribological properties were excellent. A decrease in the COF with a load increase was explained by the Hertzian contact model. The COF value obtained from the ball-on-disk tests under a constant load in the period of steady-state friction was approximately equal to 0.05 for the nc-WC/aC coating, and slightly less for the nc-TiC/a-C one, which is a really low value for a dry sliding friction. This low value of the friction coefficient has been attributed to the formation of a self-lubricating graphite-like carbon film in sliding contact containing clusters of carbon atoms with the $\mathrm{sp}^{2}$ hybridization as, e.g., in the case of the graphite plain bearings. This tribofilm was closely related to the steady-state friction during sliding and the wear mechanisms. The wear of the coatings was mainly of a micro-abrasive and adhesive nature with no significant wear of the ball surface. The wear rate $\left(W_{\mathrm{V}}\right)$ of the nc-WC/ a-C coating was equal to $0.08 \times 10^{-6} \mathrm{~mm}^{3} \mathrm{~N}^{-1} \mathrm{~m}^{-1}$, while for the nc-TiC/a-C one it was approximately four times greater $\left(0.28 \times 10^{-6} \mathrm{~mm}^{3} \mathrm{~N}^{-1} \mathrm{~m}^{-1}\right)$. The nc-TiC/ a-C coating was abraded more easily due to its lower strength and hardness, brought about by a lower volume fraction of the titanium carbides nanocrystallites (merely $3 \mathrm{pct}$ ). In contrast to that, the wear resistance of the coating with a 13 pct volume fraction of tungsten carbide nanocrystallites was much greater, plausibly due to its greater resistance to plastic deformation.

Summarizing, the coatings presented above should exhibit very good tribological properties if sliding contact with a continuous coating is ensured and if the load does not exceed the load-bearing capacity of the coating/substrate system.

\section{ACKNOWLEDGMENTS}

The results presented in this paper have been obtained within the Project "KomCerMet" (Contract No. POIG.01.03.01-14-013/08-00 with the Polish Ministry 
of Science and Higher Education) in the framework of the Operational Programme Innovative Economy 2007-2013. HRTEM investigation was conducted at the Max-Planck Institute in Stuttgart within the ESTEEM project. The authors acknowledge financial support from the European Union under the Framework 6 Program, contract for an Integrated Infrastructure Initiative. Reference 026019 ESTEEM. A partial financial support was delivered from the 7th EU FP Programme Sustainable Surface Transport, Project No. 234032 (SCP8-GA-2009-34032) Acronym POWERFUL. The authors appreciate the valuable contribution of Prof. W. Ratuszek (AGH University of Science and Technology) to XRD and GIXRD investigation.

\section{OPEN ACCESS}

This article is distributed under the terms of the Creative Commons Attribution License which permits any use, distribution, and reproduction in any medium, provided the original author(s) and the source are credited.

\section{REFERENCES}

1. S. Zhang, D. Sun, and X.L. Bui: in Nanocomposite Thin Films and Coatings, S. Zhang and N. Ali, eds. Imperial College Press, London, 2007, pp. 1-110.

2. T. Moskalewicz, B. Wendler, S. Zimowski, B. Dubiel, and A. Czyrska-Filemonowicz: Surf. Coat. Technol., 2010, vol. 205, pp. 2668-77.

3. T. Moskalewicz, B. Wendler, and A. Czyrska-Filemonowicz: Mater. Charact., 2010, vol. 61, pp. 959-68.

4. A.A. Voevodin, J.P. O'Neill, and J.S. Zabinski: Thin Solid Films, 1999, vol. 342, pp. 194-200.

5. J.L. Mo and M.H. Zhu: Wear, 2011, vol. 271, pp. 1998-2005.

6. K. Włodarczyk, M. Makówka, P. Nolbrzak, and B. Wendler: $J$. Achiev. Mater. Manuf. Eng., 2009, vol. 37, pp. 354-60.

7. J.C. Sánchez-López, D. Martínez-Martínez, C. López-Cartes, and A. Fernández: Surf. Coat. Technol., 2008, vol. 202, pp. 4011-18.

8. D. Martínez-Martínez, C. López-Cartes, A. Fernández, and J.C. Sánchez-López: Thin Solid Films, 2009, vol. 517, pp. 1662-71.

9. A. Czyrska-Filemonowicz, P.A. Buffat, M. Łucki, T. Moskalewicz, W. Rakowski, J. Lekki, and T. Wierzchoń: Acta Mater. 2005, vol. 53, pp. 4367-77.

10. T. Moskalewicz, W. Grogger, and A. Czyrska-Filemonowicz: $J$. Microsc., 2006, vol. 223 (3), pp. 195-99.

11. T. Bell and H. Dong: Proceedings of the 12th International Federation Heat Treatment and Surface Engineering Congress Melbourne, Australia, 2000, vol. 2, pp. 1-6.

12. B. Wendler, T. Liśkiewicz, Ł. Kaczmarek, B. Januszewicz, D. Rylska, S. Fouvry, A. Rylski, and M. Jachowicz:, in Ti-2003 Science and Technology, G. Luetjering and J. Albrecht, eds., Wiley-VCH, Weinheim, 2004, pp. 905-12.
13. T. Moskalewicz, S. Zimowski, B. Wendler, P. Nolbrzak, and A. Czyrska-Filemonowicz: Met. Mater. Int., 2014, vol. 20, pp. 26976.

14. B. Wendler, T. Moskalewicz, I. Progalskiy, W. Pawlak, M. Makówka, K. Włodarczyk, P. Nolbrzak, A. Czyrska-Filemonowicz, and A. Rylski: J. Achiev. Mater. Manuf. Eng., 2010, vol. 43, pp. $455-62$.

15. P. Stadelmann: JEMS Java Electron Microscopy Software, version 3.6907U2011, 1999Gú2011, http://cime.epfl.ch/research/jems (visited on $1 / 05 / 2013)$.

16. AnalySIS 3.1: Software CD-ROM, Soft Imaging System GmbH, 2001.

17. W.C. Oliver and G.M. Pharr: J. Mater. Res., 2004, vol. 19, pp. $3-$ 20.

18. Z.-H. Xu and X. Li: Acta Mater., 2008, vol. 56, pp. 1399-1405.

19. J.A. Thornton: J. Vac. Sci. Technol. A, 1986, vol. 4 (6), pp. 305965.

20. J.A. Thornton: Annu. Rev. Mater. Sci., 1977, vol. 7, pp. 239-60.

21. T. Moskalewicz, B. Schaffer, A. Manescu, F. Rustichelli, and A. Czyrska-Filemonowicz: Surf. Coat. Technol., 2007, vol. 201, pp. $7635-40$.

22. T. Moskalewicz, B. Wendler, F. Smeacetto, M. Salvo, A. Manescu, and A. Czyrska-Filemonowicz: Surf. Coat. Technol., 2008, vol. 202, pp. $5876-81$

23. D. Galvan, Y.T. Pei, and J.Th.M. De Hosson: Acta Mater., 2005, vol. 53, pp. $3925-34$.

24. Y.T. Pei, D. Galvan, and J.Th.M. De Hosson: Acta Mater., 2005, vol. 53 , pp. 4505-21.

25. K.P. Shaha: Ph.D. Thesis, University of Groningen, The Netherlands, 2011.

26. Y.T. Pei, C.Q. Chen, K.P. Shaha, J.Th.M. De Hosson, J.W. Bradley, S.A. Voronin, and M. Cada: Acta Mater., 2008, vol. 56, pp. 696-709.

27. J. Wosik, B. Dubiel, A. Kruk, H.-J. Penkalla, F. Schubert, and A. Czyrska-Filemonowicz: Mater. Charact., 2001, vol. 46, pp. 119-23.

28. S.B. Liu, A. Peyronnel, Q.J. Wang, and L.M. Keer: Tribol. Lett., 2005, vol. 18 , pp. 303-14

29. M. Kot, J.M. Lackner, Ł. Major, and W. Rakowski: Mater. Des., 2013, vol. 43, pp. 99-111.

30. K.L. Johnson: Contact Mechanics, Cambridge University Press, Cambridge, 1985.

31. E. Martínez, J. Romero, A. Lousa, and J. Esteve: Appl. Phys. A, 2003, vol. 77, pp. 419-26.

32. J. Mencík: Meccanica, 2007, vol. 42, pp. 19-29.

33. M. Kot, W. Rakowski, J. Lackner, and Ł. Major: Mater. Des., 2013, vol. 46, pp. 751-57.

34. I.L. Singer, R.N. Bolster, J. Wegand, S. Fayeulle, and B.C. Stupp: Appl. Phys. Lett., 1990, vol. 57, pp. 995-97.

35. T.W. Scharf, J.A. Ohlhausen, D.R. Tallant, and S.V. Prasad: $J$. Appl. Phys., 2007, vol. 101, pp. 063521-1-11.

36. Y. Liu, A. Erdemir, and E.I. Meletis: Surf. Coat. Technol., 1996, vol. 82 , pp. $48-56$.

37. S. El Mrabet, M.D. Abad, and J.C. Sánchez-López: Surf. Coat. Technol., 2011, vol. 206, pp. 1913-20.

38. S. Zimowski, W. Rakowski, and J. Grzonka: Surf. Interface Anal., 2010, vol. 42, pp. 1364-67.

39. A. Leyland and A. Matthews: Wear, 2000, vol. 246, pp. 1-11.

40. J. Musil, F. Kunc, H. Zeman, and H. Polakova: Surf. Coat. Technol., 2002, vol. 154, pp. 304-313.

41. Y.T. Pei, D. Galvan, J.Th.M. De Hosson, and A. Cavaleiro: Surf. Coat. Technol., 2005, vol. 198, pp. 44-50. 